\title{
Reactive Thrombocytosis - Aetiology And Relationship with Different Hematological Parameters, ESR, CRP in Infections
}

\author{
Bhavana Garg** and Menka Shah ${ }^{2}$ \\ ${ }^{1}$ Department of pathology, Pacific Medical College and Hospital, Bedla, Udaipur, India \\ ${ }^{2}$ Department of Pathology, Pramukhswami Medical College, Karamsad, India
}

\section{ABSTRACT}

Background: The measurements of platelet count, mean platelet volume (MPV), WBC are routinely available nowadays. The aim of this study was to determine aetiology and relationship of these parameters whether they were associated with the known markers of disease activity, erythrocyte sedimentation rate (ESR) and C- reactive protein (CRP) in infections.

Methods: This descriptive study was done on 500 patients with platelet count $>450,000 / \mu 1$ and the cause being reactive. Platelet count, WBC, MPV, ESR, and CRP were measured at the time of hospitalization.

Result: Most common cause of reactive thrombocytosis was Infections (28.8\%), Tissue damage (16.4\%), Iron deficiency anemia (16.2\%), Malignancy (9.6\%) and Inflammation (9.4\%). In infections, bacterial infections (88\%) were found to be more common. There was low degree of positive correlation between reactive thrombocytosis and WBC $(r=0.124, \mathrm{P}>0.05), \mathrm{ESR}(\mathrm{r}=.147, \mathrm{P}=0.07), \mathrm{MPV}(\mathrm{r}=.077, \mathrm{P}>0.05)$ in infections. There was significant negative correlation between reactive thrombocytosis and CRP in infections $(r=-.199, \mathrm{P}=0.017)$.

Conclusion: This study demonstrated a higher level of platelet count and lower MPV in all the patients having reactive thrombocytosis irrespective of it's etiology. There was low degree of positive correlation between platelet count and WBC, ESR and MPV in infections and a significant negative correlation with CRP. We propose that platelet parameters may be considered as reliable markers for assessment of disease activity.

Keywords: C-Reactive Protein, Erythrocyte Sedimentation Rate, Mean Platelet Volume, Platelet Count.

\section{Introduction}

Thrombocytosis refers to a platelet count above the normal value with the widespread use of electronic cell counters and the subsequent availability of a platelet count as part of a 'routine' blood count, thrombocytosis is more often observed as an unexpected finding. Thus, an elevated platelet count has become an important clinical problem for differential diagnosis. Thrombocytosis is classified according to its origin into primary and secondary forms. [1] The term primary thrombocytosis refers to a persistent elevation of platelet count due to clonal thrombopoiesis as it occurs in chronic myeloproliferative or in some myelodysplastic disorders. ${ }^{[2]}$ Secondary thrombocytosis is due to a variety of underlying conditions. ${ }^{[3]}$ Short-lived secondary thrombocytosis is observed in conditions such as acute bleeding, trauma, major surgical procedures or after severe physical exertion. In contrast, secondary thrombocytosis associated with malignancy, chronic infection ${ }^{[4]}$, iron deficiency or chronic inflammatory diseases may persist for a longer time. CRP is an acute phase protein secreted by the liver in response to inflammatory cytokines. Levels of CRP increase very rapidly in response to trauma, inflammation, infection, tissue necrosis and surgery. ESR is elevated in a wide range of organic disease.
ESR is not a specific and diagnostic test for any disease. However, it is helpful in differentiating functional from organic disease. To determine the aetiology and correlation with WBC, MPV, ESR and CRP of an elevated platelet count, we reviewed the medical records on 500 individuals in whom a platelet count of greater than $450,000 / \mathrm{cmm}$ was encountered during a period 16 months.

\section{Materials and Methods}

The study area selected for the study was, Shree Krishna Hospital associated with Pramukhswami Medical College (PSMC) in Karamsad, dist Anand, Gujarat. The study was conducted between the period June 2010 and September 2011 over a period of 16 months._A total of 500 patients who had come to OPD or was admitted in Shree Krishna Hospital, Karamsad having reactive thrombocytosis were taken up for the study. All the samples which were received by the Central Diagnostic Laboratory, Shree Krishna Hospital, Karamsad with requisition form for investigations from the respective OPD's or Wards and were found to have accidental thrombocytosis. The cause for thrombocytosis was found to be reactive after taking the clinical details from the consulting physician's or surgeons. The information thus collected was compiled in the master chart \& also subjected to statistical analysis. 
Statistical analysis was done using the Cross tabulations for categorical data \& correlation for continuous data in the SPSS ver.19 programme.

\section{Following parameters were included in my study:}

Histogram The sample was run on the automated blood cell counter (Sysmex KX-21, K-1000) to know the platelet count, WBC, and MPV

Erythrocyte Sedimentation Rate Done by westergen tube method

C-Reactive Protein Done by Latex agglutination test using qualitative method.

Inclusion criteria: All patients who had come to OPD and was admitted in hospital (booked or emergency) having reactive thrombocytosis (platelet count $>450,000$ / $\mu \mathrm{l}$ ), where requisition for laboratory investigations was received by Central Diagnostic Laboratory, Shree Krishna Hospital were included in the study.

Exclusion criteria: Patients having platelet count more than $4.5 \mathrm{lakh} / \mu \mathrm{l}$, but this was normal for their age as in paediatrics. Patient having thrombocytosis due to Myeloproliferative disorders (polycythemia vera, chronic myeloid leukaemia, chronic idiopathic myelofibrosis, essential thrombocytosis). Patient having thrombocytosis which is autonomous (primary) and not reactive (secondary)

\section{Result}

A total of 500 patients with the platelet count $>450,000 /$ ul was observed during the study period. The various underlying conditions associated with reactive thrombocytosis are listed in (Table 1). Majority of cases were in between 38-56 years (31\%) and $19-37$ years $(26 \%)$ (Figure 1). Almost equal number of cases was studied in both the genders, males (50.8\%) and females (49.2\%). The percentage of all causes of reactive thrombocytosis were more studied in males except Iron deficiency anemia and Burns which were more common in females.

Most common cause of reactive thrombocytosis was Infections (28.8\%), Tissue damage (16.4\%), Iron deficiency anemia (16.2\%), Malignancy (9.6\%) and Inflammation $(9.4 \%)$. In infections, bacterial infections $(88 \%)$ were found to be more common (Figure 2). Platelet count ranging from $450000-600000 / \mathrm{cmm}$ was seen with WBC $4000-11000 / \mathrm{cmm}$ in 24 cases of infections (16.7\%). Whereas WBC ranging from 11001-20000/cmm was seen in 44 cases of infections (30.6\%). There was low degree of positive correlation between reactive thrombocytosis and $\mathrm{WBC}$ in Infections $(\mathrm{r}=0.124, \mathrm{P}>0.05)$ (Figure 3 ). Platelet count ranging from $450000-600000 / \mathrm{cmm}$ was seen with ESR 0-20 (mm $\left.1^{\text {st }} \mathrm{hr}\right)$ in 37 cases of infections $(25.7 \%)$. Whereas ESR ranging from $21-40\left(\mathrm{~mm} 1^{\text {st }} \mathrm{hr}\right)$ was seen in 33 cases of infections (22.9\%). There was low degree of positive correlation between reactive thrombocytosis and ESR in Infections $(r=.147, \mathrm{P}=0.07)$ (Figure 4). MPV was normal (7.2-11.7fL) in 82 cases of infections (56.9\%) with platelet count ranging from $450000-600000 / \mathrm{cmm}$. Whereas MPV was normal in 34 cases of infections (23.6\%) with platelet count was ranging from $601000-750000 / \mathrm{cmm}$ and 19 cases of infections (13.2\%) with platelet count ranging from $751000-900000 / \mathrm{cmm}$. There was low degree of positive correlation between reactive thrombocytosis and MPV in infections $(r=.077, \mathrm{P}>0.05)$ (Figure 5). CRP was positive in 52 cases of infections (36.1\%) and negative in 57 cases of infections $(39.6 \%)$ with platelet count ranging from $450000-69900 / \mathrm{cmm}$. CRP was positive in 17 cases of infections (11.8\%) and negative in 11 cases of infections (7.6\%) with platelet count ranging from 700000-89900/ $\mathrm{cmm}$. There was significant negative correlation between reactive thrombocytosis and CRP in infections $(r=-.199$, $\mathrm{P}=0.017$ ) (Figure 6). Correlation was also done between all the cases of reactive thrombocytosis and MPV. A significant negative correlation was found between them, $\mathrm{r}=-0.128, \mathrm{P}=0.004$ ( $\mathrm{p}$ value significant at 0.01 ) (Table 2 ).

Table 1: Table showing causes of Reactive Thrombocytosis.

\begin{tabular}{|c|l|l|l|}
\hline S.NO & Causes & No. of cases & Percentage\% \\
\hline 1. & Infections & 144 & 28.8 \\
\hline \multirow{2}{*}{2.} & $\begin{array}{l}\text { Tissue damage } \\
\text { a) Trauma }\end{array}$ & 42 & 8.4 \\
\cline { 2 - 4 } & b) Fracture & 16 & 3.2 \\
\hline \multirow{2}{*}{3.} & c) Post operative & 14 & 2.8 \\
\cline { 2 - 4 } & d) Burns & 10 & 2.0 \\
\hline & a) Ironia deficiency anemia & 81 & 16.2 \\
\cline { 2 - 4 } & b) Megaloblastic anemia & 1 & 0.2 \\
\hline
\end{tabular}




\begin{tabular}{|c|c|c|c|}
\hline S.NO & Causes & No. of cases & Percentage $\%$ \\
\hline \multirow[t]{2}{*}{4.} & $\begin{array}{l}\text { Neoplastic } \\
\text { a) Malignant }\end{array}$ & 48 & 9.6 \\
\hline & b) Benign & 2 & 0.4 \\
\hline 5. & Inflammation(non-tuberculosis) & 47 & 9.4 \\
\hline 6. & Diabetes mellitus & 32 & 6.4 \\
\hline 7. & Tuberculosis & 30 & 6.0 \\
\hline 8. & Poisoning & 10 & 2.0 \\
\hline \multirow[t]{2}{*}{9.} & $\begin{array}{l}\text { Haemolytic anemia } \\
\text { a) Thalassemia major }\end{array}$ & 7 & 1.4 \\
\hline & b) Sickle cell anemia & 2 & 0.4 \\
\hline 10. & Post splenectomy & 5 & 1.0 \\
\hline 11. & Hemorrhage & 4 & 0.8 \\
\hline 12. & Myocardial infarction & 2 & 0.4 \\
\hline 13. & CCF (ASO positive) & 1 & 0.2 \\
\hline 14. & Low birth weight & 1 & 0.2 \\
\hline 15. & Drug reaction & 1 & 0.2 \\
\hline \multicolumn{2}{|r|}{ Total } & 500 & 100.0 \\
\hline
\end{tabular}

Table 2: Correlation of platelet count with MPV in reactive thrombocytosis (irrespective of its etiology).

\begin{tabular}{|l|l|l|l|}
\hline \multicolumn{5}{|l}{} & & Platelet count & MPV \\
\cline { 2 - 4 } & & & \\
\cline { 2 - 4 } & Pearson Correlation & 1 & $-.128^{* *}$ \\
\cline { 2 - 4 } & Sig. (2-tailed) & & .004 \\
\cline { 2 - 4 } WBC & $\mathrm{N}$ & 500 & 500 \\
\hline \multirow{3}{*}{ **. Correlation is significant at the 0.01 level (2-tailed). } & Pearson Correlation & $-.128^{* *}$ & 1 \\
\cline { 2 - 4 } & Sig. (2-tailed) & .004 & 500 \\
\cline { 2 - 4 } & $\mathrm{N}$ & 500 & \\
\hline
\end{tabular}

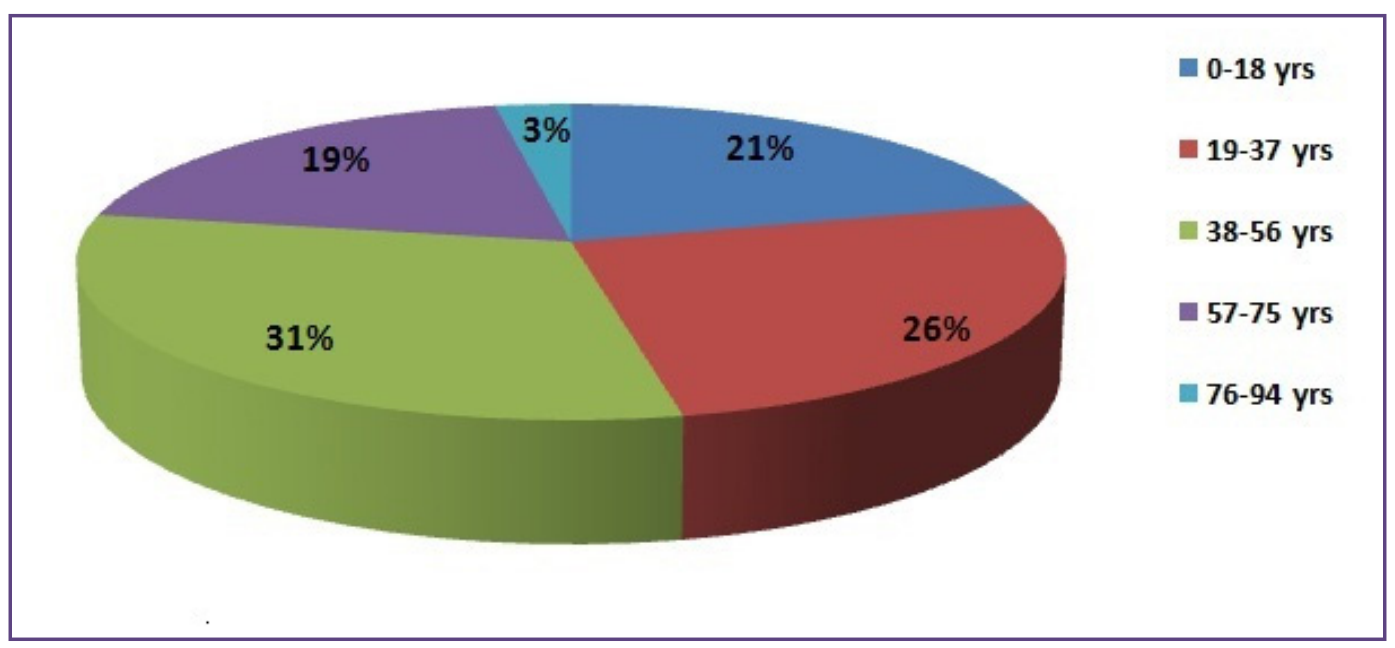

Fig. 1: Number of cases in relation to age group. 


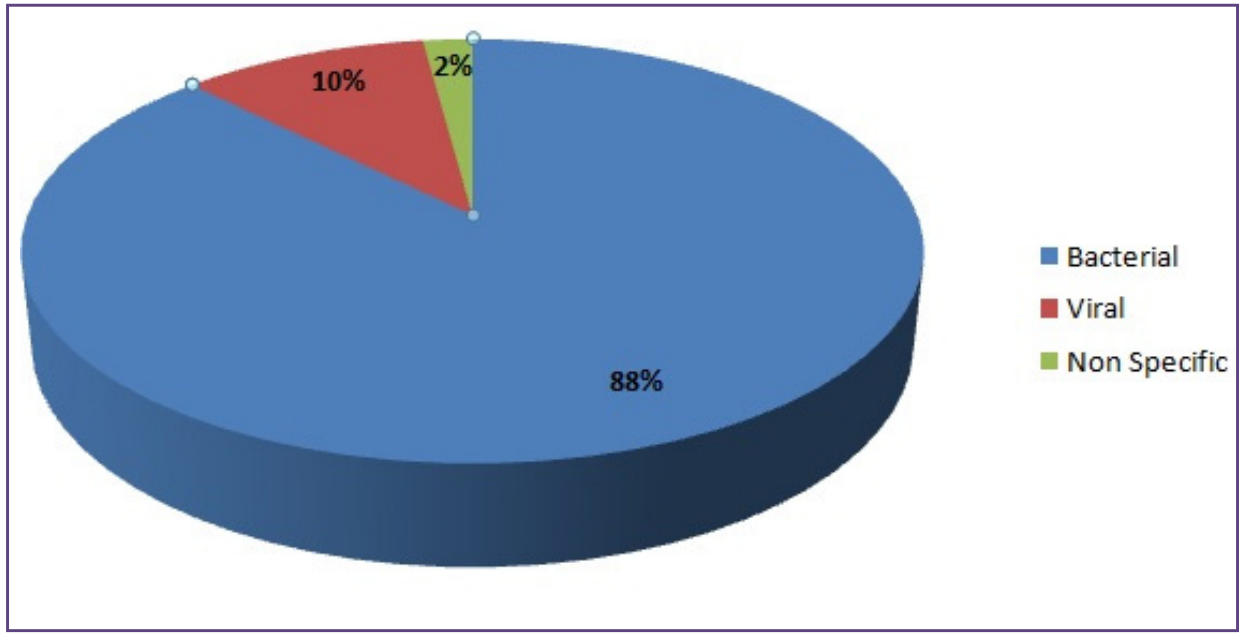

Fig. 2: Number of cases in relation to type of infection.

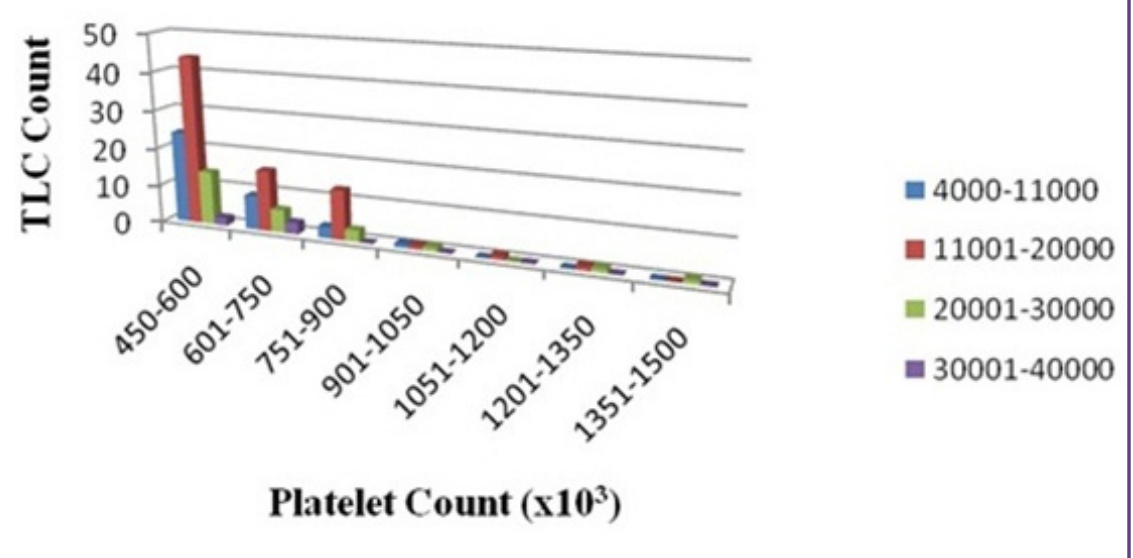

Fig. 3: Correlation of platelet count with TLC in infections.

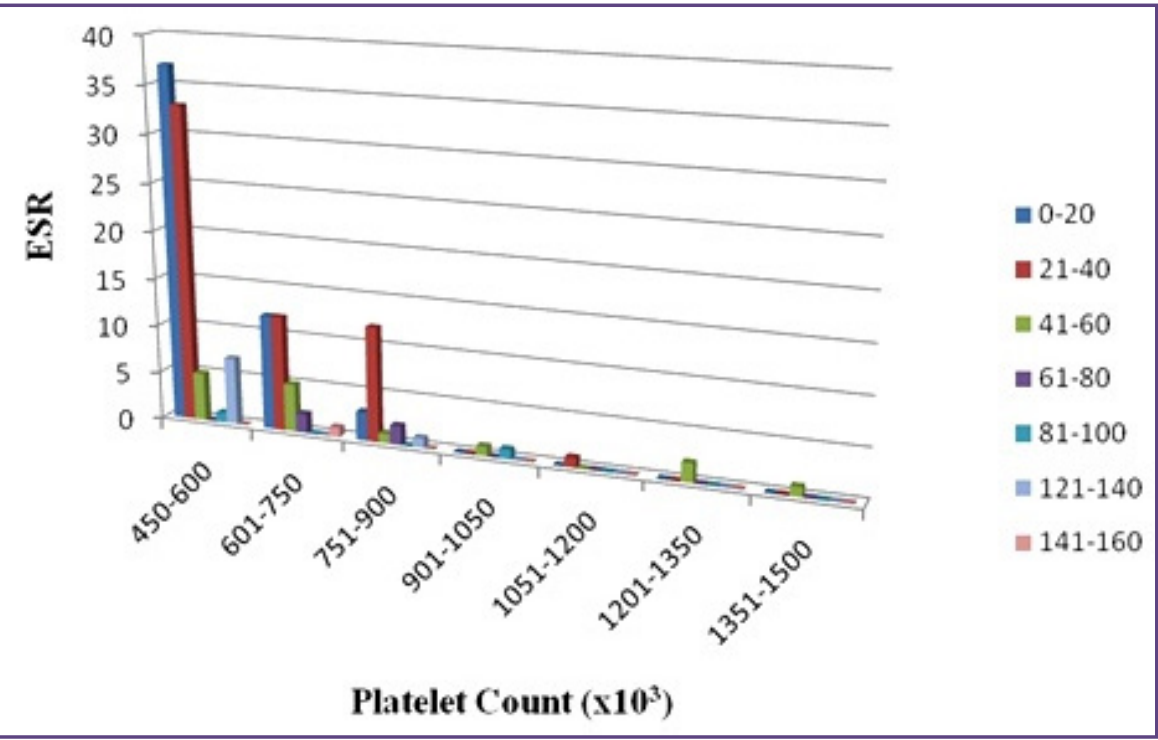

Fig. 4: Correlation of platelet count with ESR in infection.

Annals of Pathology and Laboratory Medicine, Vol. 7, Issue 8, August, 2020 


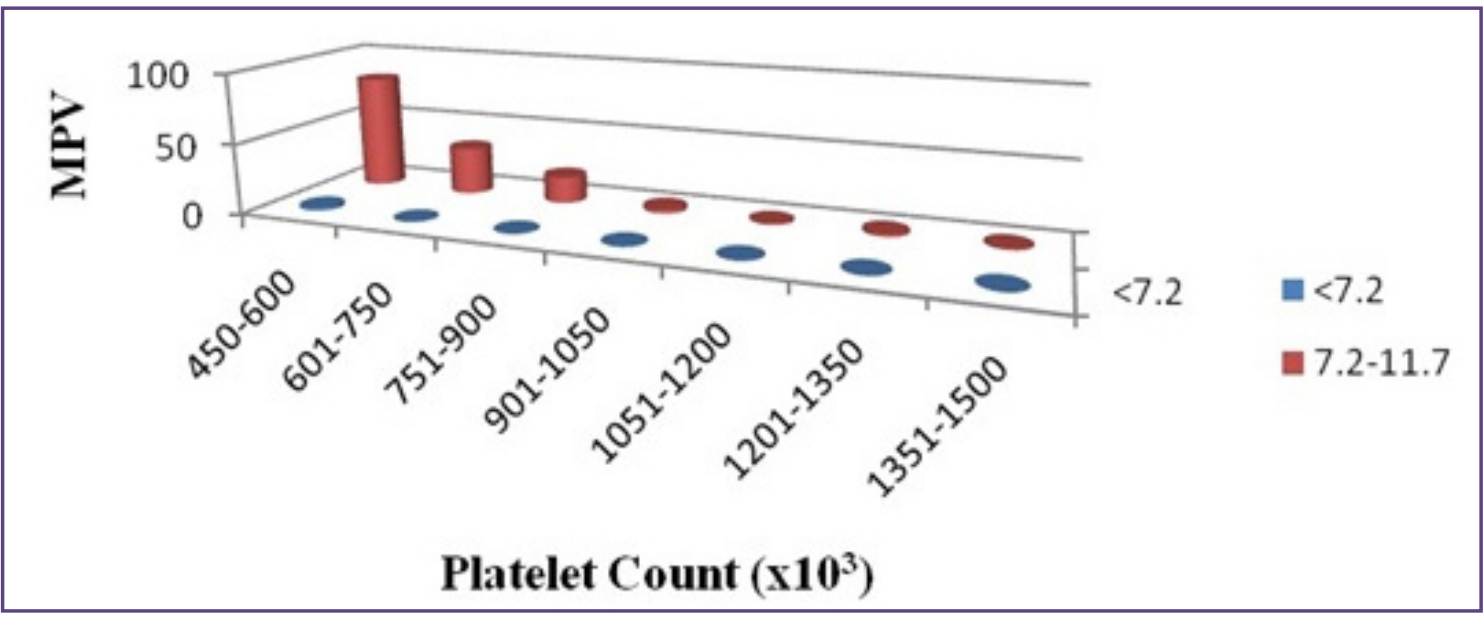

Fig. 5: Correlation of platelet count with MPV in infection.

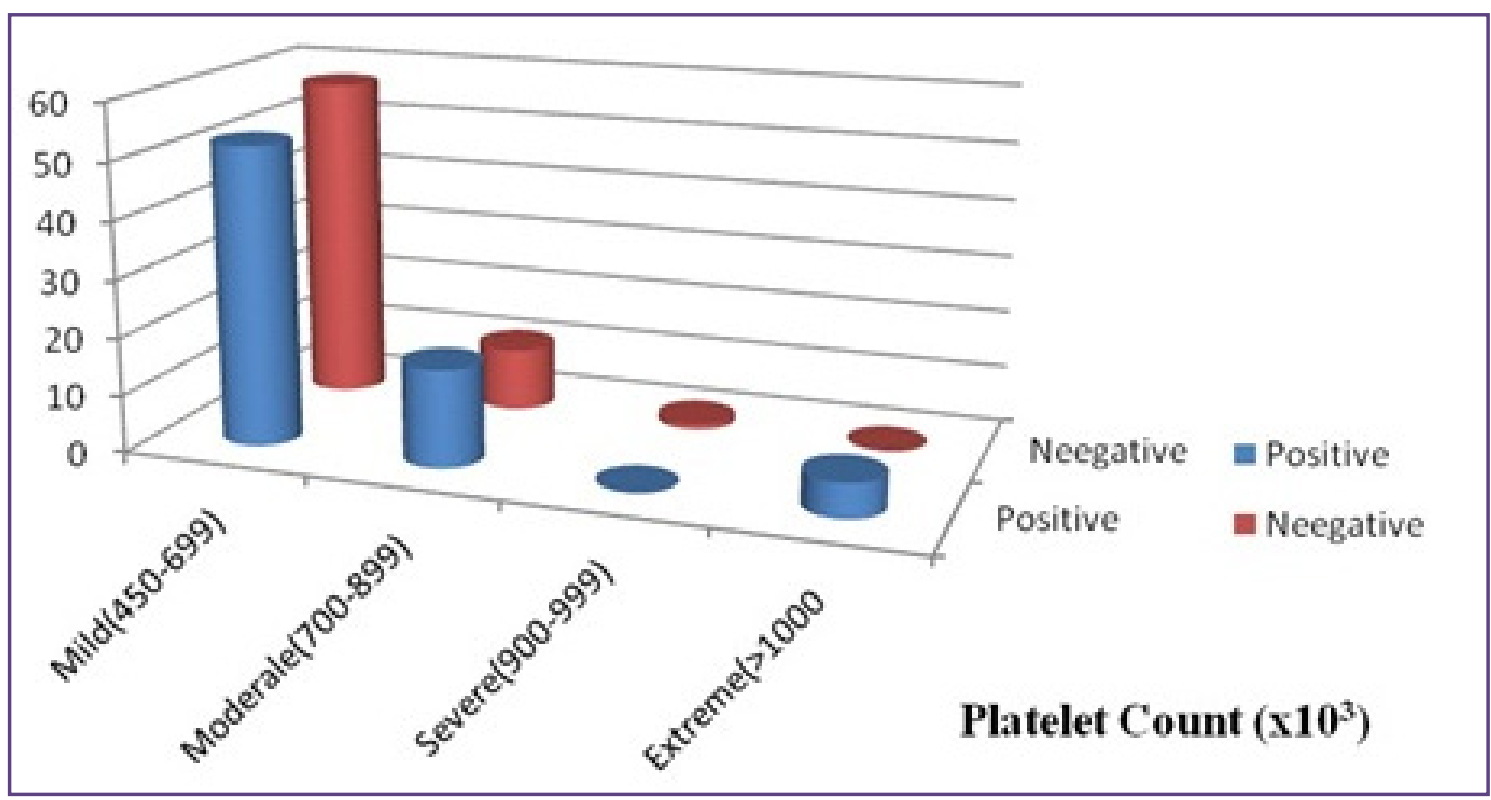

Fig. 5: Correlation of platelet count with MPV in infection.

\section{Discussion}

In present study the most common cause of reactive thrombocytosis was found to be infection $28.8 \%$, tissue damage $16.4 \%$, iron deficiency anemia $16.2 \%$, malignancy $9.6 \%$, inflammation (non-tuberculosis) $9.4 \%$, diabetes mellitus $6.4 \%$, tuberculosis $6.0 \%$, poisoning $2.0 \%$, haemolytic anemia $1.8 \%$, hemorrhage $0.8 \%$, myocardial infarction $0.4 \%$, Low birth weight and drug reaction $0.2 \%$ respectively.

The aetiology of reactive thrombocytosis was also studied in the paediatric age (0-18 years) comprising 105 cases $(21 \%)$ out of total 500 cases. The causes of reactive thrombocytosis were found to be almost similar to adults. (remove this paragraph)
In children, infections $24.7 \%$, anemia $21.9 \%$, tissue damage 21.9, haemolytic anemia 5.7\%, inflammation (nontuberculosis) $5.7 \%$, poisoning $5.7 \%$ and tuberculosis $4.8 \%$ were common causes studied. (remove this paragraph also)

The study also showed that among the infections most common was bacterial infection $87.5 \%$, viral $10.4 \%$ and non-specific $2.1 \%$ respectively. Main causes included infections ${ }^{[16]}$ like upper and lower respiratory tract, urinary tract infection, gastroenteritis, septic arthritis, generalised sepsis, meningitis, pancreatitis, and hepatitis.

In this study reactive thrombocytosis due to IDA was found in $16.2 \%$ of cases. Higher incidence of iron deficiency anemia in the present study was probably due to higher prevalence of nutritional anemia in our country. Most of 
patients with IDA were females of low socioeconomic status, having poor diet. Nagai $\mathrm{T}$ et al ${ }^{[5]}$ reported a case of IDA with marked thrombocytosis (platelet $>100,000 / \mathrm{cmm}$ ) that was complicated by central retinal vein occlusion. However, in present study no case of IDA associated with complications were studied.

In the present study reactive thrombocytosis due to $\mathrm{TB}$ was found in $6.0 \%$ of the cases. However Bayness RD et al ${ }^{\left[{ }^{[6]}\right.}$ have mentioned reactive thrombocytosis was common occurrence due to $\mathrm{TB}$, while according to MC Donald ${ }^{[7]}$ and Omar et al ${ }^{[8]} \mathrm{TB}$ was an uncommon occurrence.

Among the malignant lesions, carcinoma oral cavity $20.8 \%$, carcinoma breast $14.6 \%$ and carcinoma lung $14.6 \%$ were found to be more commonly associated with reactive thrombocytosis. This was similar to the study conducted by Levine S P et al ${ }^{[4]}$ which showed that malignancy of lung and breast was more frequently associated with reactive thrombocytosis. In my study carcinoma oral cavity was the most common association with reactive thrombocytosis, as it is the most common malignancy in India due to the tobacco chewing.

Regarding the correlation of platelet count with TLC, ESR and MPV in infections showed low degree of positive correlation. However, this kind of correlative study has been not carried out earlier.

Correlation of platelet count with CRP showed significant negative correlation. However with extreme reactive thrombocytosis CRP was directly correlated. It is the CRP serum concentration that is strongly suggestive of infection. Study conducted by group of authors - Show AC, $\left[{ }^{9]}\right.$ Peltola Het al, $\left[{ }^{10]} \mathrm{MC}\right.$ corthy P L et al, ${ }^{[11]}$ Rose $\mathrm{P}$ et al, ${ }^{[12]}$ found that $\mathrm{CRP}$ value $>100 \mathrm{mg} / \mathrm{l}$ was strongly associated with bacteraemia. They also showed that CRP was increased in bacterial infection and lower in viral or fungal infections.

One similar study done by Rowe I F et al. ${ }^{[13]}$ in which they had shown that serum CRP concentration rises after most forms of infections, inflammation, tissue damage and malignant neoplasia.

Correlation was also done between all the cases of reactive thrombocytosis and MPV. A significant negative correlation was found between them, $r=-0.128, \mathrm{P}=0.004$ ( $\mathrm{p}$ value significant at 0.01 ). Almost similar study was done by Zareifar S and Farahmand Far M. ${ }^{[15]}$

Similar study was done by Van der Lelie et al. ${ }^{[14]}$ and Von dem Borne et al. ${ }^{[14]}$ They found a mean platelet volume that is lower than that found in normal subjects. In normal subjects a non-linear inverse relation between platelet count and mean platelet volume has been found: the higher the platelet count, the lower the mean platelet volume. The low mean platelet volume in reactive thrombocytosis might be an extrapolation of this relation

\section{Conclusion}

Majority of cases were in between the age group 38-56 years $31 \%$. There was no prominent sex predilection, males $50.8 \%$ and females $49.2 \%$. Among 500 cases the most common causes of reactive thrombocytosis were found to be Infections (28.8\%), Tissue damage (16.4\%), Iron deficiency anemia (16.2\%), Malignancy (9.6\%) and Inflammation (9.4\%), Diabetes mellitus 6.4\%, Tuberculosis $6.0 \%$, Poisoning 2.0\%, Haemolytic anemia $1.8 \%$, Haemorrhage $0.8 \%$, Myocardial infarction $0.4 \%$, Low birth weight and Drug reaction $0.2 \%$ respectively. Among the infections, bacterial infection $87.5 \%$ was most common. The causes of reactive thrombocytosis in children were similar to adults. Most common cause being infections and iron deficiency anemia in children. (remove these lines marked in red) In infections: TLC, ESR and MPV showed low degree of positive correlation between them and reactive thrombocytosis. There was significant negative correlation between reactive thrombocytosis and CRP in infections $(r=-.199, P=0.017)$. A significant negative correlation was found between the entire cases of reactive thrombocytosis (irrespective of the aetiology) and $\operatorname{MPV}(\mathrm{r}=-0.128, \mathrm{P}=0.004)$.

\section{Acknowledgements}

Dr. Menka Shah, Dr. Monica Gupta, Dr. Keyuri Patel, Dr

Sanjay Chaudhari, Dr. Neena Doshi, Dr. Faruq Mulla, Dr. Kriti Rathod and Dr. Munira Jhabuawalla all contributed equally to this work and are considered as senior authors.

Dr. Menka Shah provided opinions for interpreting results of the study and manuscript preparation. Rest all other authors took parts in the whole progress of this study such as drawing conclusion.

\section{Funding:}

Nil

\section{Competing Interests}

NIL

\section{Reference}

1. Levine SP. Thrombocytosis. Wintrobe's Clinical Hematology A Waverly Company. 9thed, 1993;2:1648-55,1836-1923.

2. Vannucchi AM, Barbui T. Thrombocytosis and Thrombosis. Hematology Am Soc Hematol Educ Program.2007;363-70

3. Schafer AI. Thrombocytosis. N Engl J Med. 2004;350:1211-9 
4. Levine SP. Thrombocytosis. Wintrobe's Clinical Hematology A Waverly Company. 9thed, 1993;2:1648-55,1836-1923.

5. Nagai T, Komatsu N, Sakata Y, Miura Y, Ozawa K. Iron deficiency anemia with marked thrombocytosis complicated by central retinal vein occlusion. Intern Med 2005; 44: 10901092.

6. Baynes RD, Bothwell TH, Flax $\mathrm{H}$ et al - Reactive thrombocytosis in pulmonary tuberculosis. J Clin Pathol 1987; 40:676-679.

7. MC Donald TP. A comparison of platelet size, Platelet count 35 s incorporation as assay for thrombopoietin. Br J Hematol 1978;38:257-67.

8. Omar M, Jogessar VR, Kamder MC. Thrombocytosis associated with tuberculosis peritonitis tubercle 1983; 64: 295-6.

9. Shaw AC. Serum C-reactive protein concentration in patient with viral or bacterial infection. J Clin Pathol. 1991; 44:546-599.

10. Peltola H, Holmberg C. Rapidity of C-reactive protein concentration in detecting potential septicaemia. Pediatr Infect Dis $1983 ; 2: 374-6$.
11. Mc Carthy PL, Frank AL, Ablow RC, Master SJ, Dolan TF Jr. C-reactive protein test in differentiation of bacterial and viral pneumonia. J Pediatr 1978; 92:454-6.

12. Rose PE, Johnson SA, Meakin M, Mackie PH, Stuart J. Serial study of C-reactive protein during infection in leukaemia. J Clin Pathol 1981; 34:263-6.

13. Rowe IF, Worsley AM, Donnelly P, Catvsky D, Goldman JM, Pepys HB. Measurement of serum C-reactive protein concentration after bone marrow transplantation for leukaemia. J Clin Pathol 1984; 37:263-66.

14. Van der Lelie, Von dem Borne et al. Platelet volume analysis for differential diagnosis of thrombocytosis. J Clin Pathol 1986; 39:129-133.

15. Zareifar S and Farahmand Far M. Changes in plateletcount and MPV during infections and inflammatory disease and their correlation with ESR and CRP. J Clin Lab Anal. 2014 may; 28(3) 245-248.

16. Schattner A, Kadi J, Dubin I. Reactive thrombocytosis in acute infectious disease. European journal of internal medicine Feb 19, 2019; volume 63, 42-45.

*Corresponding author:

Dr. Bhavana Garg, Flat No.703, fatehpura road, sukhadia circle, Udaipur, India, 313001

Phone: +91 9999782822

Email: bhavanagarg203@gmail.com 